\title{
Video Article \\ Measures of Heart and Ventilatory Rates in Freely Moving Crayfish
}

\author{
Sonya M. Bierbower ${ }^{1}$, Robin L. Cooper ${ }^{1}$ \\ ${ }^{1}$ Department of Biology, University of Kentucky
}

Correspondence to: Sonya M. Bierbower at sbierbower.uky@gmail.com

URL: https://www.jove.com/video/1594

DOI: doi:10.3791/1594

Keywords: Physiology, Issue 32, invertebrate, autonomic nervous system, behavior, crustacean

Date Published: 10/15/2009

Citation: Bierbower, S.M., Cooper, R.L. Measures of Heart and Ventilatory Rates in Freely Moving Crayfish. J. Vis. Exp. (32), e1594, doi:10.3791/1594 (2009).

\section{Abstract}

The fear, flight or fight response serves as the fundamental physiological basis for examining an organism's awareness of its environment under an impending predator attack. Although it is not known whether invertebrates posses an autonomic nervous system identical to that of vertebrates, evidence shows invertebrates have a sympathetic-like response to regulate the internal environment and ready the organism to act behaviorally to a given stimuli. Furthermore, this physiological response can be feasibly measured and it acts as a biological index for the animal's internal state. Measurements of the physiological response can be directly related to internal and external stressors through changes in the central nervous system controlled coordination of the cardio-vascular and respiratory systems. More specifically, monitoring heart and ventilation rates provide quantifiable measures of the stress response not always behaviorally observed. Crayfish are good model organisms for heart and ventilatory rate measurements due to the feasibility of recording, as well as the rich history known of the morphology of the crayfish, dating back to Huxley in 1888 , and the well-studied typical behaviors.

\section{Video Link}

The video component of this article can be found at https://www.jove.com/video/1594/

Protocol

\section{Introduction}

Organisms must exhibit a wide range of behaviors to respond to threatening stimuli and changes in the environment. The autonomic response is well studied in vertebrates as the fight or flight response in which the sympathetic nervous system physiologically readies the internal environment (Carpenter, 1976; Nicholls et al., 2001). It is through physiological changes that an organism can regulate the stress response and alter behavior to react to an impending attack or environmental change. Evidence shows that the cardio-vascular system is tightly connected with the respiratory system thus enabling the internal environment to respond and implement a response. It is well known that the autonomic control of the respiratory and cardiovascular systems can regulate oxygen availability and nutrients to specific target tissues needed for an impending behavioral response.

In vertebrates, the autonomic and physiological response is so well evolved; it would seem likely that complex invertebrates would similarly possess a developed response system (Schapker et al., 2002; Zavarzin, 1941). Even though vertebrates and invertebrates are very different systematically; highly developed invertebrates require the rapid cardiovascular and respiratory response to respond in a fight or flight manner. For many invertebrates, a sympathetic-like physiological response can be quantified. Dating back to 1927, many of the very early studies have been conducted in invertebrates, specifically using arthropods in general (Alexandrowicz, 1932; Orlov, 1927; Zavarzin, 1941).

Crayfish are known to exhibit a wide range of rapid behaviors as well as the ability to assess and respond to environmental stimuli. Very early studies have noted a sympathetic-like response of an immediate and rapid response of defense posturing (Bethe, 1897; Huxley, 1880; Shuranova et al., 2006; Wiersma, 1961). The adult crayfish heart is neurogenic since the beat and rhythm are controlled by the central nervous system (Alexandrowicz, 1932; Yamagishi and Hirose, 1997; Yamagishi et al., 1997; Wilkens, 1999). Routinely, measurement of an animal's heart rate $(\mathrm{HR})$ provides a direct measure of excitability and readiness of the internal environment. In crayfish, an increase in HR is noted during defense posturing when presented with a perceived threatening stimulus (Listerman et al., 2000). This type of nervous system response was also shown in spiny lobsters (Yazawa and Katsuyama, 2001).

The ventilatory system is also neuronally controlled with a ventilatory central pattern generator (VPG) responsible for oxygen uptake across the gills by the pumping action of two specialized appendages termed scaphognathites (Mendelson, 1971). A single scaphognathite resides in each branchial chamber at the anterior ends and draws water across the gills by a rhythmic movement (Pasztor, 1968). The VPG, like with the heart, can be modulated by many factors. Previous work in the crab, Cancer magister shows cardiac and ventilatory rhythm can be altered by central control through command neurons (Wilkens et al., 1974). In addition, activity of the VPG is known to change with changes in the interna response and with social interactions or environmental changes in crustaceans (Burmistrov and Shuranova, 1996; Cuadras, 1979, 1980; Li et al., 2000; Listerman et al., 2000; McMahon and Wilkens, 1983; Schapker et al., 2002; Shuranova et al., 2002; Wilkens, 1976). As seen in the 
crayfish, ventilatory activity (VR) can vary depending on the internal state and changes in VR can be recorded during unexpected external stimuli (Shuranova et al., 1993; Shuranova et al., 2002).

Due to the dependability and feasibility of HR and VR measures, the future questions to be asked are endless. As noted previously, work has been done to examine the autonomic response during social interactions and environmental disturbances. Interestingly, many areas are left to be explored such as examination of the autonomic response during natural hormonal changes and/or other physiological processes occurring in the organism. Possible future directions may also examine sympathetic-like responses during mating and olfactory chemical reception. Most importantly, physiological responses may provide greater insights into an organism response to the environment when compared to behavioral observations since animals do not always respond behaviorally when they are readying themselves internally. Thus, the physiological measurement provides a biological index for assessing an organism's internal state which may explain overall changes in an organism.

\section{Methods}

\section{Electrocardiograms recording (ECGs) procedures for heart and ventilation rates}

Before beginning to wire a crayfish, preparation of wires is required. Cut two insulated stainless steel wires (diameter 0.005 inches and with the coating 0.008 inches; A-M Systems, Carlsburg, WA) long enough to insert into the crayfish and adequately reach an impedance detector (UFI, model 2991). Remove insulation $(\sim 0.5 \mathrm{~mm})$ by fire on the ends of both wires which will be inserted into the carapace. Be careful not remove too much insulation as a bare wire on the outside of the animal must be recoated to prevent short circuiting impedance recordings. Then, using forceps bend the burned ends of the wires in a 90 angle for placement into the carapace. Be sure that the inserted portion of the wire is not too long because this could do damage to internal organs. For feasibility of inserting the wires into a plastic tube (which protects the wires), it is best to loosely twist the wires together. If recording heart and ventilation rates, repeat the above steps a second time and the two sets of wires can be loosely braided together before placement into the plastic tubing. Be sure to designate the wires for heart and ventilation rate so as to not confuse which wires attach to which impedance detector for recording. It is best to label the wires or cut one pair shorter than the other in the beginning.

To feasibly and safely wire the crayfish, it is best to wrap the claws and legs (leaving the back and one side exposed) in wet cloth or paper towels to eliminate injury to the person and/or crayfish (Figure 1).

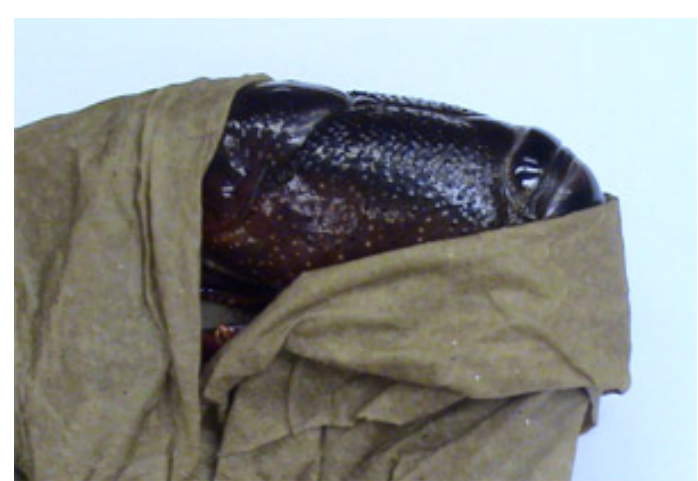

Figure 1. Wrapping of the chelipeds and legs of the crayfish. Wrapping the crayfish in a

wet paper towel will prevent injury to the person and the crayfish. The wrapping will hinder the ability of the crayfish to move the chelipeds and legs.

To begin the wiring process, it is best to begin in the gill chamber since carapace thickness varies with each crayfish and excess force can cause damage to internal organs, thus by beginning in the gill chamber, excessive pressure is less likely to kill the crayfish as compared to the thoracic chamber. The first hole is made by using a fine point scalpel and just large enough for a wire to be inserted under the cuticle in the rostral area of the gill chamber (i.e., prebranchial chamber to monitor ventilatory rate; Schapker et al., 2002). A large hole will have excessive hemolymph loss and will not seal properly and this will increase the probability of the wires not remaining in the designated hole. Once the wire is in place, drop a small amount of glue (cyanoacrylate ester) and accelerator (HobbyTown USA, Lexington, KY) onto the wire. The use of the fast drying glue reduces handling stress of the animals. Be careful to place only a small amount of accelerator onto the cuticle since this is toxic to the crayfish and will cause death. It is best to immediately wipe any excess accelerator off with paper towel. Repeat these steps for the second wire in the gill chamber. These two wires are placed to span the scaphognathite (respiratory organ) to insure a strong accurate impedance measure during each scaphognathite movement (Figure 2). To get an accurate recording, be sure that the second wire is not placed outside the gill chamber and into the thoracic chamber. 


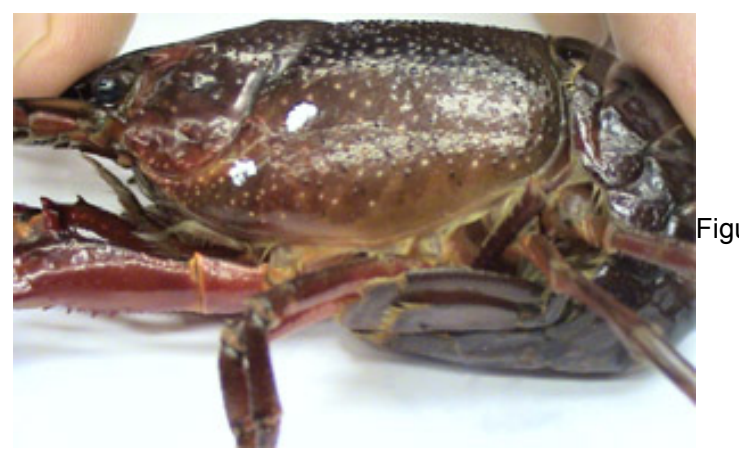

the carapace represent points for the stainless steel wires to be placed under the cuticle. The wires span the scaphognathite and measure movement through dynamic impedance.

The steps for wiring heart rate in the thoracic chamber is the same as above except the wires are placed under the dorsal carapace directly over the heart and span the heart in a rostral-caudal arrangement (Figure 3). This placement will ensure a strong accurate impedance measure during each heart contraction (Listerman et al., 2001).

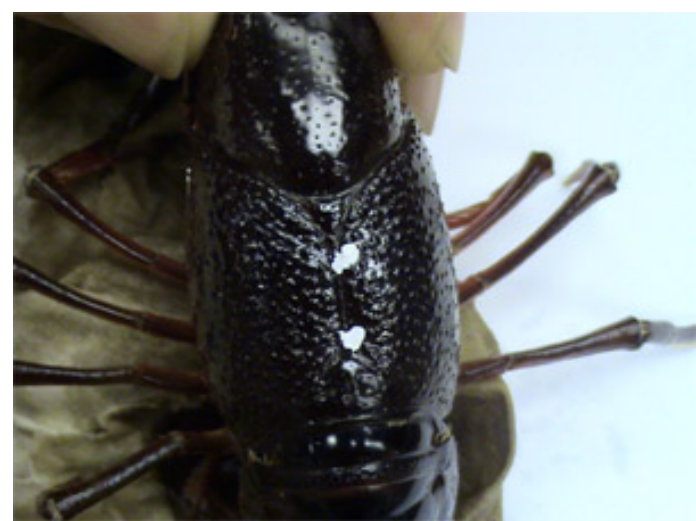

Figure 3. Placement of stainless steel wires in the thoracic chamber. The white dots

on the carapace represent points for the stainless steel wires to be placed under the cuticle. The wires span the heart in a rostral-caudal arrangement. This will allow for measures of heart contraction through dynamic impedance.

Once placement of all four wires is complete, mix an instant adhesive (Eastman, 5-min drying epoxy) and coat the holes for each location as well as the wires. Once the wires and drilled holes are adequately covered, use the remaining epoxy to hold the plastic tubing to the back of the crayfish. This will ensure that the wires will not be pulled out of the holes in future handlings. Since the epoxy takes a few minutes to dry, hold or place the crayfish in a container without water until the epoxy is no longer sticky to the touch. Once the epoxy is dry, wash the crayfish in water to remove excess chemicals and place them back into an aquatic environment. To ensure the health of the crayfish, it is best to change the water in approximately one hour to remove any chemicals not previously removed. As noted from previous investigators, we found that prolonged handling alters the physiological measurements due stress for a time duration of $24 \mathrm{~h}$ to 3 days (Wilkens et al., 1985); therefore, animals should be left for 2 to 3 days before any experimentation.

To record ECGs, connect the wires from the crayfish to impedance detectors. The two wires spanning the heart (measure HR) should be attached to a single impedance detector and likewise for the two wires spanning the scaphognathite (measure VR). The impedance detector measures dynamic resistance between the two stainless steel wires. These signals are recorded by connecting the detector on-line to a PowerLab via a PowerLab/4SP interface (AD Instruments). All events are measured and calibrated with the PowerLab Chart software version 5.5.6 (AD Instruments, Australia). To begin, set an acquisition rate at $4 \mathrm{kHz}$. The large deflections will represent heartbeat and ventilation rate. For ease in counting each HR/VR, a smoothing function can applied to the data set. If 100 points were smoothed (i.e. averaged) the resultant trace will depict only the heartbeats. The heart rates can be determined by direct counts of each beat over 10-s intervals and then converted to beats per min (BPM).

\section{References}

1. Alexandrowicz, J. S. The innervation of the heart of Crustacea. I. Decapoda. Wuart. J. Microsc. Sci., 75: 181-249 (1932).

2. Bethe, A. Vergleichende Untersuchungen uber die Funtionen des Zentrainervensystems der Arthropoden. Pfluger s Arch. Ges. Physiol., 68: 449-545 (1897).

3. Burmistrov, Y. M. and Z. P. Shuranova. Individual features in invertebrate behavior: Crustacea. In: Abramson Cl, Shuranova ZP, Burmistrov YM (eds) Russian Contributions to Invertebrate Behavior. Praeger, Westport, Connecticut. Pp. 111-144 (1996).

4. Carpenter, M. B. The autonomic nervous system. Human Neuroanatomy, 7th ed. The William \& Wilkins Co, Baltimore, MD, pp. 191-212 (1976).

5. Cuadras, J. Heart rate and agonistic behavior in unrestrained crabs. Mar. Behav. Physiol., 6: 189-196 (1979).

6. Cuadras, J. Cardiac responses to visual detection of movement, mechanostimulation and cheliped improsed movement in hermit crabs. Comp. Biochem. Physiol. A, 66: 113-1171 (1980). 
7. Huxley, T.H. The Crayfish: An introduction to the study of zoology, New York: D. Appleton and Company, 1880, v. XXVIII of the international Scientific Series. Reprinted 1973, 1974, 1977, MIT Press, Cambridge, MA (1880).

8. Li, H., L.R. Listerman, D. Doshi, and R. L. Cooper. Use of heart rate to measure intrinsic state of blind cave crayfish during social interactions. Comp. Bichem. Physiol., 127A: 55-70 ( 2000).

9. Listerman, L.R., J. Deskins, H. Bradacs, and R.L. Cooper. Heart rate within male crayfish: social interactions and effects of 5-HT. Comp. Biochem. Physiol., 125A: 251-263 (2000).

10. McMahon, B.R., and J.L. Wilkens. Ventilation, perfusion and oxygen uptake. In: Mantel, L., Bliss, D. (eds), Biology of Crustacea, 6 . Academic Press, New York, pp. 289-372 (1983).

11. Mendelson, M. Oscillator neurons in crustacean ganglia. Science, 171: 1170-1173 (1971).

12. Nicholls, J.G., A.R., Martin, B.G. Wallace, and P.A. Fuchs. From Neuron to Brain. Sinauer Assoc., Sunderland, MA, USA. pp. 315-317 (2001).

13. Orlov, Y. Das Magenganglion des Flußkrebses, Ein Beitrag zur vergleichenden Histologis des sympathischen Nervensystem. Z. Mikrosk. Anat. Forschung 8 (1), 67-102 (1927)

14. Pasztor, V.M. The neurophysiology of respiration in decapod Crustacea: The motor system. Can. J. Zool., 46: $585-596$ (1968).

15. Schapker, H., T. Breithaupt, Z. Shuranova, Y. Burmistrov, and R.L. Cooper. Heart rate and ventilatory correlative measures in crayfish during environmental disturbances and social interactions. Comp. Biochem. Physiol., A 131: 397-407 (2002).

16. Shuranova, Z.P., A.V. Vekhov, and Y.M. Burmistrov. The behavioral reactions of fresh-water crayfish to sensory exposures: the autonomic components. Zh. Vyssh Nerv. Deiat Im I P Pavlova, 43: 1159-1169 (1993).

17. Shuranova, Z.P. and Y.M. Burmistrov. Ventilatory activity in free moving crayfish is indicative of its functional state and perceiving external stimuli. In: The Crustacean Nervous System (K. Wiese, ed.). Springer, Berlin. Pp. 526-535 (2002).

18. Shuranova, Z.P., Y.M. Burmistrov, J.R. Strawn, and R.L. Cooper. Evidence for an autonomic nervous system in decapod crustaceans. Inter. J. Zool. Res. 2 (3): 242-283 (2006).

19. Wiersma, C.A.G. Reflexes and the central nervous system. In: Waterman, T.H., (ed). The physiology of Crustacea, vol II, Sense organs, integration, and behavior. Academic Press: New York. Pp. 241-279 (1961).

20. Wilkens, J.L. Neuronal control of respiration in decapod Crustacea. Fed. Proc. 35, 2000-2006 (1976).

21. Wilkens, J.L. and L.A. Wilkens. Central control of cardiac and scaphognathite pacemakers in the crab Cancer magister. J. Comp. Physiol. 90, 89-104 (1974).

22. Wilkens, J.L. The control of cardiac rhythmicity and of blood distribution in crustaceans. Comp. Biochem. Physiol. A, 124: 531-538 (1999).

23. Yamagishi, H. H. Ando, and T. Makioka. Myogenic heartbeat in the primitive crustacean Triops longicaudatus. Biol. Bull., 193: 350-358 (1997).

24. Yazawa, T. and T. Katsuyama. Spontaneous and repetitive cardiac slowdown in the freely moving spiny lobster, Panulirus japonicas. J. Comp. Physiol., 187 A: 817-824 2001.

25. Zavarzin, A.A. Ocherki po evol utsionnoj gistologii nervnoj sistemy (Essays on the evolutionary histology of the nervous system). In A.A. Zavarzin, Izbrannye trudy (Selected Works), Tom III, Izdatel stvo AN SSSR: Moskva-Leningrad, 1950 (1941). [In Russian] 